\title{
Moving From the Knowledge Economy to the Human Economy*
}

\author{
Cheryle Tewarie, Angela Escalante \\ The University of the West Indies, St. Augustine Campus, \\ Trinidad and Tobago, West Indies
}

\begin{abstract}
Converging on the notion that we must more aggressively invest in our people, there is a greater impetus to transform our region from a knowledge economy to a human economy and view that relationship as cyclically organic. The total sum of leveraging the assets resident in business skills, expertise, and resources, and university knowledge outputs can only provide compounded benefit and add greater value to building and sustaining the human economy. This paper will outline the framework, i.e., the key strategies, systems, channels, and processes that iscritical for a healthy partnership and the importance of a well-designed monitoring mechanism to track the incorporation of knowledge into the human economy. The paper will attempt to demystify the components of the “-” between university and industry and the metrics needed to support these components, inclusive of an analysis of the preconditions needed to ensure a healthy partnership and productive collaboration. Based on practical experiences and on a specific case of a university-industry collaborative project implemented in the twin island State of Trinidad and Tobago located in the Caribbean region, the paper will provide a practical framework for planning, executing, and monitoring university-industry interaction.
\end{abstract}

Keywords: human economy, knowledge economy, enablers, competitive advantage, impact

\section{Introduction}

The global financial crisis has renewed concern about whether capitalist markets are the best way of organising economic life. Would it not be better if we were to treat the economy as something made and remade by people themselves, rather than as an impersonal machine? (Hart, Laville, \& Cattani, 2010)

The term "knowledge economy" was popularized by Peter Drucker (1969) as the title of Chapter 12 in his book The Age of Discontinuity. The turn of the 20th century was characterized as a period of disruption and discontinuity in which the structure and meaning of economy, polity, and society have been radically altered. Factors of production of the recent economic age, capital, and energy as the primary wealth-creating assets were being replaced by information and knowledge. Drucker's new universe of knowledge was based on mass education and its implications in work, leisure, and leadership. He described the knowledge economy as the use

\footnotetext{
* The Paper entitled "Moving from the Knowledge Economy to the Human Economy” was presented at the International University-Industry Innovation Network Conference, June 22-28, 2015, Berlin, Germany.

Cheryle Tewarie, manager, Research Funding and Business Development, The University of the West Indies, St. Augustine Campus; Office of Research Development and Knowledge Transfer.

Angela Escalante, contract officer, The University of the West Indies, St. Augustine Campus; Office of Research Development and Knowledge Transfer.
} 
of knowledge to generate tangible and intangible values. Much of the theory was based on the explosion of new technologies and its effects on new industries, new economic borders, and the lack of policy and institutions to circumvent these changes.

Michael Porter (1998) noted that the economy had become far more dynamic and that comparative advantage had become less relevant than competitive advantage which rests on "making more productive use of inputs, which requires continual innovation.”

More than a decade later, new ideas are emerging, not the least those surrounding an economy created by humans. In order to be a human economy, according to Hart, Laville, and Cattani (2010), the economy must have at least four key characteristics: (1) It must be made and remade by people and should be of practical use in daily lives; (2) It should address a great variety of particular situations in all their institutional complexity; (3) It must be based on a more holistic conception of everyone's needs and interests; and (4) It has to address humanity as a whole and the world society we are making.

Seidman (2014) noted that mature economies have evolved from being industrial to knowledge and had arrived at a watershed moment, transitioning to human economies and catering for all of its implications. Here, he proposed, everyone is a leader doing the next right thing.

As we now, strive to invest in the development of the economy through collaboration, and as we move from the knowledge economy to the human economy, as the next level to strive to achieve competitive advantages, we attempt to focus on university-industry collaboration as a foundation for deeper economic development. Close examination of the competitive advantage model that informs the most successful or most competitive countries reveals a very heavy emphasis on the development of its human capital. As Porter (1990) noted, "National prosperity does not grow out of a country's natural endowments, its labor pool, its interest rates, or its currency's value, as classical economics insists."

\section{Transformation into a Human Economy}

Converging, therefore, on the notion that we must more aggressively invest in our people, there is a greater impetus to transform our region from a "knowledge economy" to a "human economy" and view that relationship as cyclically organic. In so doing, there ought to be a continuous examination of the performance of those prescribed factors that enable and sustain this relationship to generate the envisioned impact.

According to development indices and noted in a Review of the Economy 2013, the Human Development Index ranked Trinidad and Tobago 64 out of 187; for the Global Competitive Review, it was ranked 92 out of 148 in 2013-2014 and 89 in 2014-2015. Generally, the Caribbean displayed the levels of competitiveness and development that are reflective of the urgent need to engage new strategies that will alleviate critical restraints on human development, competiveness, and innovation. One of these major strategies is for universities to link more strategically and effectively with industry to the benefit of the universities' mission, the industries' raison d'être and to all those sectors on which each will benefit, influence, and impact.

A nation's competitiveness depends on the capacity of and rate at which its industry innovates and upgrades. Industries gain advantage overthe world's best competitors because of pressure and challenge. (Porter, 1990). The growing impetus on not only developing countries, but on all countries to be competitive and profitable, requires an increased ability to uptake and incorporate knowledge generated from valuable 
activities and leveraging networks and partnerships to increase entrepreneurial and innovative outputs all in a time-sensitive manner. This is exceedingly critical for universities in the face of increased competition for public funding and for industries as they compete for market share. Governments are increasing their support for university-industry interaction as the mechanism to improve efficiency, innovation, and competitiveness and it is expected that once this environment is successfully nurtured, there will be faster economic development of a country/region.

Universities themselves focus more on non-traditional activities to differentiate themselves from their competitors. These activities include conducting contracted and joint research, institutionalising systems that facilitate and engage commercialisation of research, encouraging spin off activity and identifying and sustaining various partnerships with business (United Nations Educational, Scientific, and Cultural Organization [UNESCO], 2000). Universities worldwide have set up mechanisms to deal with the changing demands as in the establishment of the Office of Research Development and Knowledge Transfer at the St. Augustine Campus of The University of the West Indies. The foundation of these activities is having a comprehensive knowledge and relationship management system upon which the partnership relies to identify, assess, manage, and monitor the performance of the relationship(s) at all stages. It is recognised that the generation of knowledge is a foundation element, but if the capacity to take up this knowledge and transform it into useful applications is not adequately realised via the interactionor partnership, then its value can be compromised and it can quickly become irrelevant.

Resident within the university is a critical mass of knowledge, expertise, and living laboratories where new knowledge is constantly being created. In most societies, universities play a major role in fuelling the knowledge economy and have now to engage its constituents in a manner that results in successfully utilising this knowledge and opportunities toward measurable development results as it helps to create a more innovative and competitive region.

From the perspective of industry where the focus is on the triple bottom line, universities are seen as having capabilities to explore several connections, channels, and practices in support of each pillar of the triple bottom line, namely, economic, social, and environmental. Understanding the value propositions of both sides will serve to ensure that the university as well as industry derive mutual benefits. The total sum of leveraging the assets resident in industry business skills, expertise and resources, and university research and knowledge outputs can only provide compounded benefit and add greater value to defining, building, and sustaining the human economy.

\section{Use of Indicators}

Seppo and Lilles (2012) have described a number of input, impact, and output indicators measuring different types of university-industry cooperation. We will selectively examine how these translate into tangible outputs. The viability of the interaction as well as the degree of success of the collaboration will be measured in several ways, including tracking the performance of the collaboration over time.

This paper will demystify the components of the "-” between university and industry cooperation and the metrics needed to support these components, inclusive of an analysis of the preconditions needed to ensure a healthy partnership and productive collaboration. This paper will present a model designed and executed at The University of the West Indies in collaboration with two major business partnerswith the support of government. It will outline the framework, i.e., the key strategies, systems, channels, and processes that are critical for a 
healthy partnership and a keenly designed monitoring mechanism to derive positive impact of incorporating knowledge into the human economy in an extractive region of Trinidad and Tobago.

The paper will be divided into three sections. Section I will begin with a brief literature review of university-industry indicators, followed by the authors' description and analysis of the components that make up a successful collaboration. Section II will illustrate a practitioner's case of a successful university-business collaboration and apply a practical framework for planning, executing, and monitoring university-industry interaction. Section III will present the authors' conclusions and recommendations on the identification and establishment of effective university-industry interactions.

\section{Section I: Identifying Context and Desiging Appropriate Indicators}

\section{Literature Review}

Research on university-industry linkages has provided "a vast array of indicators and outcomes" both tangible and intangible, but there is scant research on the "how" in managing university linkages. Numerous reports, symposia, think pieces, and descriptions of collaboration exist, but a number of constraints are noted. These may include partners' differences in mission and objectives, organizational structures, effectiveness, and arrangements for collaboration along with potential barriers including culture, policies, expectations, and the conduct between/among partners (Geisler \& Rubenstein, 1989).

Korf, Baaken, and Macpherson (2013) described university-industry linkages as "two-way linkages between university and government entities established to enable the diffusion of creativity, ideals, skills, and people with the aim of creating mutual value over time...." They note that the research provides limited theoretical development and practical advice on successfully managing collaboration throughout the phases of university-industry linkage evolution. They propose a team-based model with high levels of involvement in the process that can lead to development of personal and economic ties. They recognise that many barriers need to be overcome including different backgrounds, purposes, cultures, and norms of each partner. Three phases of development of collaboration were examined: initiation, engaging, and continuing engagement. They found that communication at all stages of relationship development in the form of open professional dialogue and informal discussions will help to influence trust. They note that each partner needs to understand changes in relational success factors over time. It was important for universities to understand the evolving factors of long term linkages to establish guidelines for successful partnering. However, they note that the most challenging constraints affecting university-industry linkages remain: (1) differing structure/organization of partners; (2) differing value-added for partners; and (3) a shift in expectations over the life of the project as a response to technology, markets, partners' changes in policy, and even funding.

Ryan and Heim (1997) suggested that university-industry linkages can take any one of three forms: (1) institutionally directed; (2) industry directed; and (3) government catalysed. They recommend that there should be a clear and mutual understanding of each partner's expectations. In other words, value-added for each partner must be clearly articulated from the onset. The importance of building value-added incentives and outcomes, developing effective linkages, taking time to understand the culture, traditions, and values of each partner will lead to enhancement of trust and communication, factors which they felt would help to nourish and sustain the partnership. They recognised the importance of an outreach structure within the university that can 
adequately respond to partnership opportunities.

Much research and discussions of collaborative activities between universities and industry emphasise, the importance of using proper indicators including input-output indicators, as well as relationship-based indicators. For example, Seppo and Lillies (2012) highlighted a number of key indicators: (1) channels of interaction; (2) level of impact; (3) performance indicators; (4) intensity of collaboration; (5) economic impact; and (6) productivity (increasing productivity means that businesses are improving the size of income relative to expenses thus becoming more competitive). They suggest that both the knowledge and the transfer of it should be measured as this would provide good practice and networking opportunities. Both quantitative and qualitative methods are recommended, the latter serving to provide an understanding of the changes taking place as the collaboration evolves. Many indicators have been prescribed to measure successful university-industry collaboration, and while it is difficult to determine appropriate indicators, those selected should be clear and relevant to the partnership and servethe intended outcome.

Cyert and Goodman (1997) took an organizational learning perspective and note that relationships are opportunities for learning. Like Korf, Baaken, and Macpherson (2013), they view a team-based approach as one of the strategies to facilitate transfer and creation of knowledge between institutions. Further, they suggest that multiple relationships among partners, for example, internships, research collaboration, and tasks help to reinforce the relationship, so that partners have a better understanding of each other.

Marzo-Navarro, Pedraja-Iglesias, Marta, and Rivera-Torres (2009) took a relational marketing approachand analyse the university-industry approach from a business perspective. They found that firms [industry] that experience greater satisfaction in their relationships with universities feel more committed and would be more willing to form lasting partnerships.

As noted, research on university-industry collaboration provides varying models and perspectives, for example, stakeholder relationship, network theories, organisational learning, and relationship marketing perspective among others. However, there is general agreement that while models, indicators, prescriptions, theories, and discussions, and a vast array of indicators both tangible and intangible that may be applied to un-ravel the meaning of the "-", there is actually very little research on the "how" or the strategies in managing university-industry linkages. The characteristics and expectations of partners belonging to different sectors of economies are viewed as major barriers to successful linkages.

\section{Demystifying the Mysterious “_” What Are the Components of This Link?}

The phrase "university-industry collaboration” is becoming increasingly popular for good reasons. There is tremendous benefit to be derived from leveraging university-industry interaction for immediate and potential future mutual benefits to economies as a whole. The traditional culture of many universities, however, is not evolving fast enough to survive in a competitive market place even though some universities are becoming more entrepreneurial in their interaction with society and industry. Clark (1998) suggested that "The university-environment relationship is characterized by a deepening asymmetry between environmental demand and institutional capacity to respond, resulting in a need for an overall capacity to respond flexibly and selectively to change.” This further justifies the imperative between universities and industries to forge collaborative partnerships.

Many entities take it for granted that the mere identification of a seemingly suitable partner is sufficient, but this is only the beginning. Much thought must be invested prior to the collaboration in identifying and 
defining the constituents of the "-”. One must consider the meaning and requirements of each constituent, each of which will depend on the specific initiative being agreed upon, the resources, i.e., the human, physical, and financial as sets of each partner and the due consideration of incorporating additional collaborators and as certaining their respective roles and impact. These additional collaborators may include government, state enterprises, non-governmental organizations, and the community. The "-" also refers to the agreed-upon governing structure arrangement or collaboration between university and industry that will facilitate the arrangement or collaboration, the ease of harmonization of operational architecture, i.e., the rules, regulations, procedures, and policies of each collaborator and the agreed-upon mechanisms for reporting, monitoring, and evaluation.

Anatomy of the "-». The foundation of university-industry interaction is often based on the fact that any sustainable relationship requires both tangible and intangible guiding parameters working collaboratively and harmoniously together to ensure desirable outcomes. The parameters may be viewed as analogous to structure of the human anatomy:

1. The head-governing structure. Contractual agreement that outlines "inter alia" terms and conditions of engagement and termination, ownership of intellectual property, and scope of work to be done;

2. The heart—expectations, relationship management, trust, open communication, good will, and "going the extra mile;"

3. The nervous system — monitoring, evaluation, and sustainability strategies;

4. The skeletal system—rules, regulations, policies, and procedures of each partner.

\section{Selection of Indicators “You Cannot Manage What You Cannot Measure”}

Indicators can be viewed as analogous to road signals: (1) green-keep going, on the right track; (2) yellow-caution, pay attention to threats to the relationship ecology; and (3) red-stop and re-evaluate, possible need to re-design. With the identification of sound and appropriate indicators and effective tracking and monitoring of the performance of these indicators, attaining red status should be rare. Indicators are important for the productive process over the life of the collaboration and for fostering a healthy collaborative environment, where expectations of various partners are satisfied.

Categories of indicators. There are several categories of indicators, including: (1) Project indicators which serve to monitor and evaluate the performance of the implementation activities for attainment of outputs and team deliverables; and (2) Partnership indicators which serve to monitor the satisfaction of the basic requirements of the partnership governed by the contract. As mentioned previously, indicators can be "hard" and "soft," "tangible and codified," or "intangible or tacit." As far as possible, intangible or qualitative indicators (such as trust, timely responses, and action) must be expressed and documented. These considerations leave less room for misunderstanding or misinterpretation of expectations as the interaction progresses and mature.

Measuring successful university-industry collaboration. It is critically important that the indicators selected to measure result and impacts of the university-industry interaction are judiciously identified. Selection of inadequate or inappropriate indicators will naturally result in misalignment with the expected outcome(s). Seppo and Lilles (2012) noted that different types of cooperation will require different indicators and it is difficult to select the most appropriate indicators to reflect policy and achievement. They categorise and describe three categories of indicators: input indicators, output indicators, and impact indicators. They provide 
a framework for university-industry cooperation in the categories of "output" and "impact" indicators that reflect both medium and long term impact. They conclude that it is difficult to determine the most appropriate indicates for successful university-industry cooperation. We examine indicators, that from our experiences, best identify a family of indicators-primary and supporting for a strong university-industry collaboration.

Figure 1 illustrates the three primary indicators that will form the framework of the exploration phase among partners.

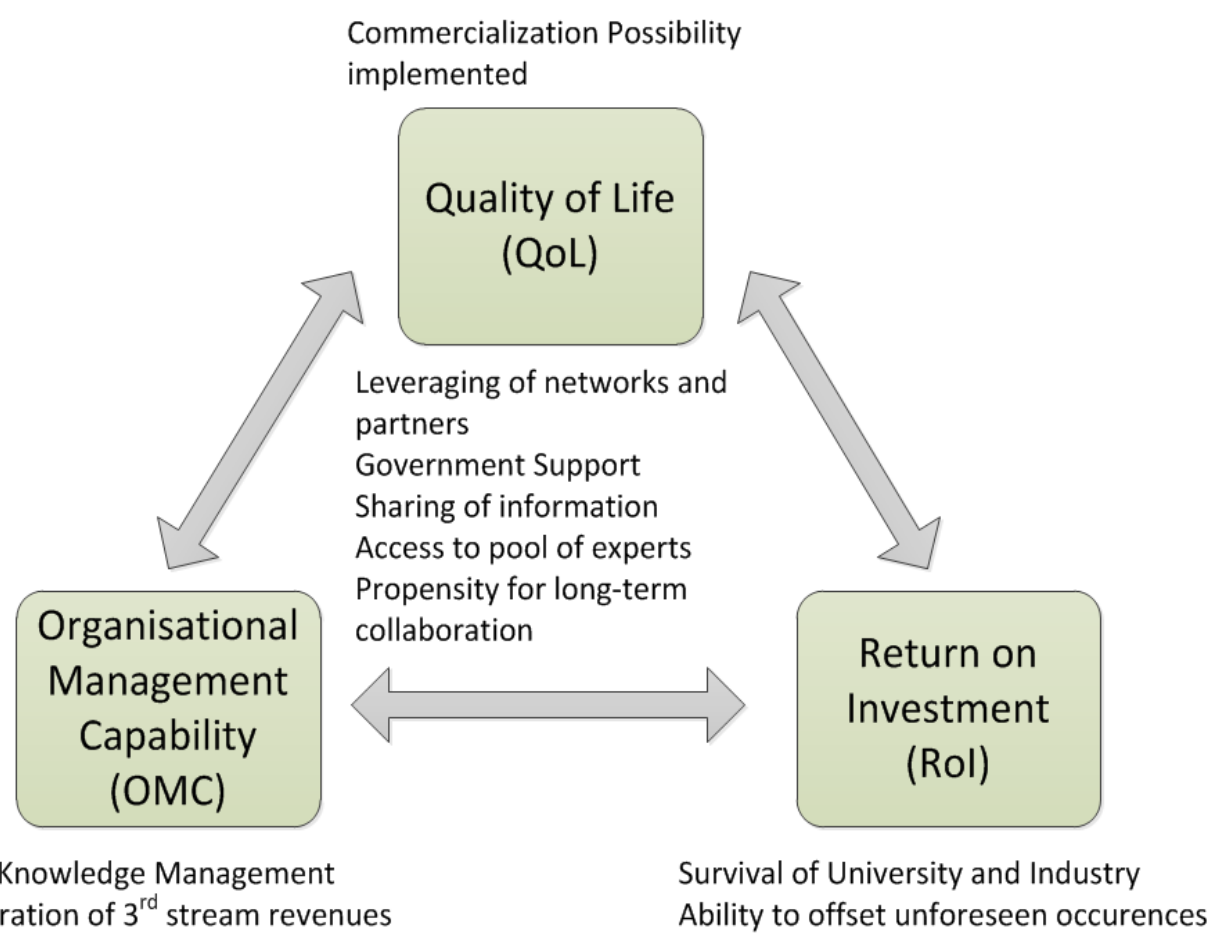

Figure 1. Three primary indicators of interaction success.

Quality of life is an important indicator for universities and public sectors (governments), whose goal is to improve the quality of life of its citizens, whether we view these as national, regional, or international.

Return on investment is an important indicator for private sector and industry to ensure that the impact outweighs the initial investment.

Organisational management capability is an important indicator for all collaborators to ensure that each partner possesses the requisite composition of processes, structures, rules, regulations, and intrinsic skill sets to bring the outcome to fruition.

Each of these primary indicators depends on a series of supporting indicators for more accurate assessment of collaboration viability. These are described in the following interaction matrix (see Table 1).

\section{The Interaction Matrix}

In 2015, as part of the work of the Office of Research Development and Knowledge Transfer of The University of the West Indies, Tewarie and Escalante developed a matrix based on the above three primary indicators to assess and determine the value of collaboration outcomes. 
Table 1

Matrix of Indicators and Measurement of Interaction Performance

\begin{tabular}{|c|c|c|}
\hline Indicators & Measurement indicators & Means of verification \\
\hline \multirow{3}{*}{ Leveraging networks and partnerships } & $\begin{array}{l}\text { Good communication plan } \\
\text { among/between the main partners }\end{array}$ & Sanctioned communication plan \\
\hline & Similar values & Partners' raison d’être submitted \\
\hline & $\begin{array}{l}\text { Medium-long term commitment to the } \\
\text { agreed upon goals (of the intervention). }\end{array}$ & $\begin{array}{l}\text { Signed document (memorandum of } \\
\text { agreement and contract). }\end{array}$ \\
\hline $\begin{array}{l}\text { Government's support to improve } \\
\text { effectiveness, innovation, and } \\
\text { competitiveness. }\end{array}$ & $\begin{array}{l}\text { Alignment with government's } \\
\text { development agenda }\end{array}$ & $\begin{array}{l}\text { National policy } \\
\text { In-kind (facilitation) or financial } \\
\text { commitment from the government }\end{array}$ \\
\hline $\begin{array}{l}\text { Faster economic development of a } \\
\text { country/region. Sustained impact. }\end{array}$ & $\begin{array}{l}\text { Articulation of each partners' commitment } \\
\text { (at the level of the organisation) and } \\
\text { mutual (at the level of the interaction) } \\
\text { goals. }\end{array}$ & $\begin{array}{l}\text { Signed document } \\
\text { Clear documented distinction between } \\
\text { project/intervention performance and } \\
\text { collaboration performance } \\
\end{array}$ \\
\hline To survive & $\begin{array}{l}\text { Contextual awareness of the situation to } \\
\text { be resolved and of each other's position }\end{array}$ & Partner’s brief-position statement \\
\hline \multirow{2}{*}{$\begin{array}{l}\text { Offset/mitigate against or capitalize on } \\
\text { unforeseen occurrences that can arise. }\end{array}$} & $\begin{array}{l}\text { An agile collaboration (partners) will } \\
\text { quickly re-conform itself to mitigate } \\
\text { unforeseen occurrences. }\end{array}$ & $\begin{array}{l}\text { Articulated commitment by partners for a } \\
\text { successful collaboration }\end{array}$ \\
\hline & A receptive organizational structure & $\begin{array}{l}\text { Internal policy that governs } \\
\text { university-industry interaction }\end{array}$ \\
\hline \multirow{2}{*}{$\begin{array}{l}\text { Generation of new knowledge, capacity } \\
\text { for uptake knowledge, opportunities to } \\
\text { publish and conduct additional research. }\end{array}$} & Knowledge toolkits designed & $\begin{array}{l}\text { Agreement to co-share new knowledge } \\
\text { generated collaborative research agenda } \\
\text { proposed. }\end{array}$ \\
\hline & System to capture and transfer knowledge & Research information management system \\
\hline To generate third stream revenues & Knowledge of financial position & Financial statements \\
\hline \multirow{3}{*}{$\begin{array}{l}\text { Sharing of cutting-edge research and } \\
\text { information }\end{array}$} & Reports & Publications \\
\hline & Informed research agenda & $\begin{array}{l}\text { Approved multidisciplinary research } \\
\text { agenda }\end{array}$ \\
\hline & $\begin{array}{l}\text { Proposed solutions to industry's most } \\
\text { critical needs }\end{array}$ & Proposal to industry for engagement \\
\hline \multirow{2}{*}{$\begin{array}{l}\text { Pool of experts that can easily be } \\
\text { "assembled" to solve an issue or a } \\
\text { challenge. }\end{array}$} & $\begin{array}{l}\text { Facilitates organizational growth-for all } \\
\text { partners }\end{array}$ & Performance targets are being met \\
\hline & \begin{tabular}{|l} 
Encourages deeper and long term \\
participation among partners.
\end{tabular} & Long term agreement \\
\hline Propensity for long-term collaboration & $\begin{array}{l}\text { Some degree of synchronization among } \\
\text { policies that encourage or guide } \\
\text { collaboration, mandates, mission, and } \\
\text { vision. }\end{array}$ & $\begin{array}{l}\text { Signed agreement for long term } \\
\text { collaboration }\end{array}$ \\
\hline $\begin{array}{l}\text { The prospect of commercialization } \\
\text { partnerships. }\end{array}$ & $\begin{array}{l}\text { Industry’s indication of the commercial } \\
\text { potential of a particular output(s). }\end{array}$ & $\begin{array}{l}\text { Memorandum of understanding (soft } \\
\text { agreement) for continued support } \\
\text { patents, trade secrets, and trade marks. }\end{array}$ \\
\hline
\end{tabular}

\section{Section II: Indicators at Work: A Case Study by The University of the West Indies}

Practitioner's case "Developing and Implementing a Framework for Local Economic Development for Regions with Extractive Industries.”

\section{Background}

The project was informed by a socio-economic baseline study of six communities in the south western peninsula of Trinidad. The assessment focused on the link between an extractive industry's core business activities and its impact on the local economy. While the industry had made significant contributions to the community, the base line report found that the activities over many years failed to achieve the expected 
sustainability results. Further, despite the interventions, communities showed declining economic activity and showed only marginal increases in the number of new businesses. Furthermore, the findings supported the need for various forms of collaboration between the private and public sector to facilitate further growth and development in the region.

The project "Developing and Implementing a Framework for Local Economic Development for Regions with Extractive Industries” was the result of several discussions among university and industry each of whom found a common interest as a result of collaboration.

\section{The Project}

The project is located in Trinidad and Tobago located in the Caribbean (see Figure 2). The goal of this project was to expand the adoption of regional economic development policies and strategies based on public-private interaction for economic, social, and environmental sustainability. The purpose was to support a sustainable and inclusive socio-economic growth in the south western peninsula of Trinidad and to develop and implement a Local Economic Development (LED) model for regions with extractive industries. The south western peninsulais, one of five areas in Trinidad and Tobago that has been identified as a "growth pole" or an area that has latent economic and sociocultural value that can be developed to generate economic activity within the area (see Figure 3).

The components that informed the project indicators of success were:

1. To integrate public-private actors and build institutional capabilities for LED;

2. To develop new or expanded business activities in key non energy sectors in the region;

3. To support human capital development and employability of "at risk" and marginalized groups;

4. To create and transfer of knowledge, results, and best practices on LED in extractive industries regions to key stakeholders groups.

\section{The Collaborators}

The major collaborators were identified as: (1) The University of the West Indies; (2) Atlantic liquefied natural gas (LNG); and (3) Inter-American Development Bank, Multilateral Investment Fund (IDB-MIF).

The University of the West Indies, Office of Research Development and Knowledge Transfer (The UWI-ORDKT). The UWI was founded by Royal Charter on April 2, 1962. Its mandate is to serve the manpower needs of the Caribbean region and continue to aggressively seek funding opportunities for research through various avenues including commercialization of intellectual property, spinoffs, and other knowledge transfer activities. The UWI is the first port of call for Caribbean governments seeking advice, technical expertise for policy development, strategic planning, and programme implementation. Over the past decade, the UWI had been undergoing transformation by setting up structures to form closer links with industry and to respond to a range of demands, both internal and external. The UWI has four main campuses, three of which are located in the islands of Trinidad (St. Augustine Campus), Jamaica (Mona Campus), and Barbados (Cave Hill Campus), and the fourth, an open campus to serve the needs of the non-campus territories of the Caribbean region.

The UWI-ORDKT, one of the structures set up within the UWI, supports all research and knowledge transfer activities at the St. Augustine Campus located in the twin island State of Trinidad and Tobago. In collaboration with the UWI's Central Office of Research, the ORDKT provides intelligence and early information on new initiatives and developments and on the updated priorities of major funding bodies via a research information management system which links UWI experts to national and international corporations, 
multinational organizations, governments, non-governmental organizations (NGOs), and funding agencies, provides project management and project monitoring services. It also provides guidance and mentoring to faculty engaged in grant writing and project execution.

Atlantic LNG. Atlantic LNG is the sixth largest producer of LNG in the world and is a corporate entity committed to creating sustainable opportunities for Trinidad and Tobago. It has committed itself to investing more strongly in sustainable corporate social responsibility programs in the local community and across Trinidad and Tobago and funds a chair in environmental engineering at the UWI.

Inter-American Development Bank, Multilateral Investment Fund (IDB-MIF). The IDB-MIF is the leading provider of technical assistance for the private sector in Latin America and the Caribbean. It is also one of the region's largest investors in microfinance and venture capital funds for small businesses. The MIF always works with local, mainly private partners, to help fund and execute projects. It provides grants, loans, guarantees, equity and quasi-equity, as well as advisory services to business associations, non-governmental organizations, foundations, public sector agencies, and financial institutions, and in some cases, private sector firms to support projects that benefit the underprivileged and those whose quality of life should be enhanced.

Other critical peripheral collaborators were identified, that is, those "spokes" that were perceived as being able to bring increased value during the life of the project and beyond, to ensure that the outputs and outcomes were achieved. These were "inter alia," the government of the Republic of Trinidad and Tobago as the entity to further enable the initiative, Partners of America, service volunteered for all (SERVOL), a voluntary organization, life centre, and the beneficiaries, constituting six communities in the south western region of Trinidad comprising a population of approximately 25,000.

Location of the project. Figures 2 and 3 show that the location of the project in the Caribbean and the growth poles identified. For the south western peninsula, the focus is on port development, fishing industry, manufacturing, and support services and agriculture.

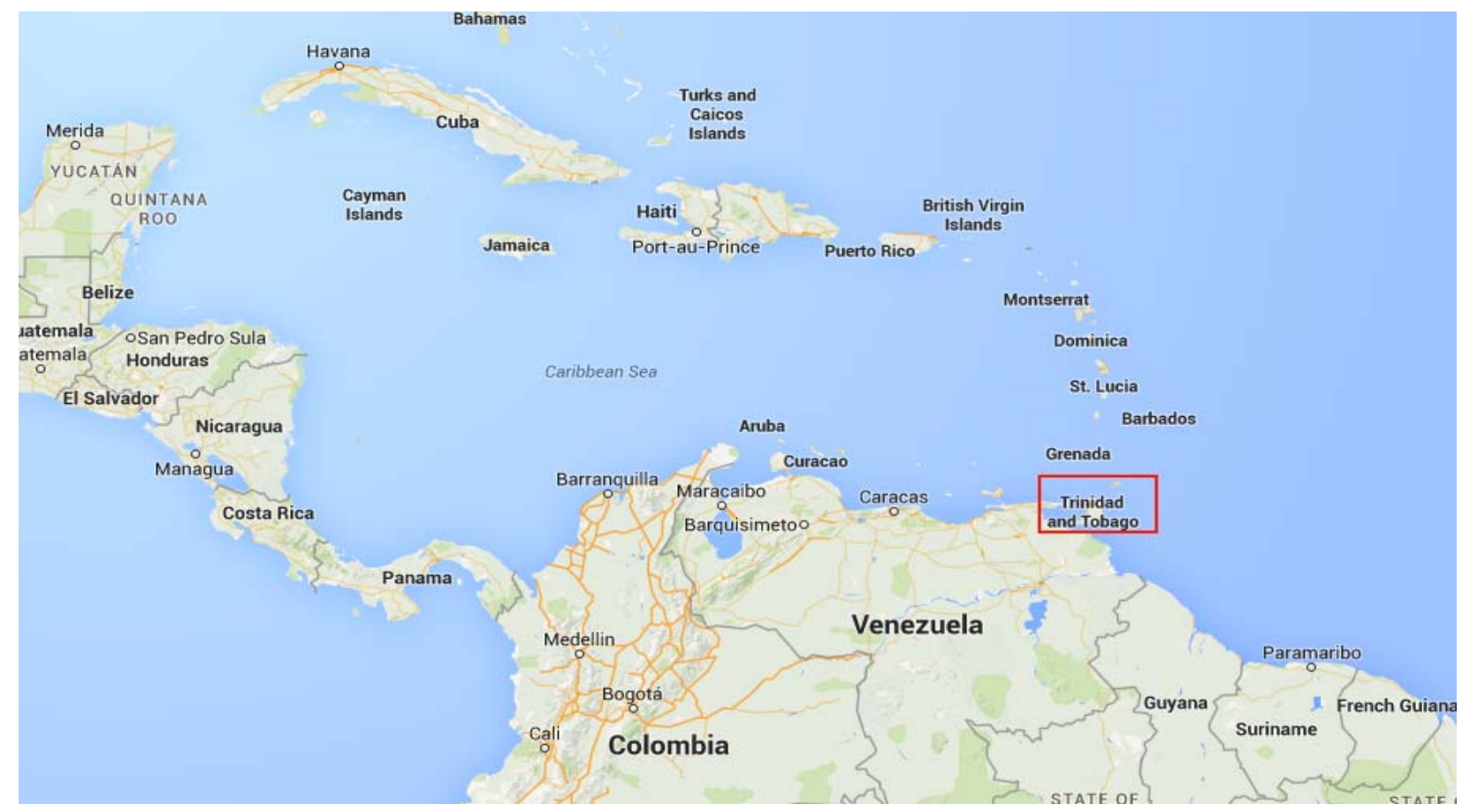

Figure 2. Geographical location of Trinidad and Tobago. 

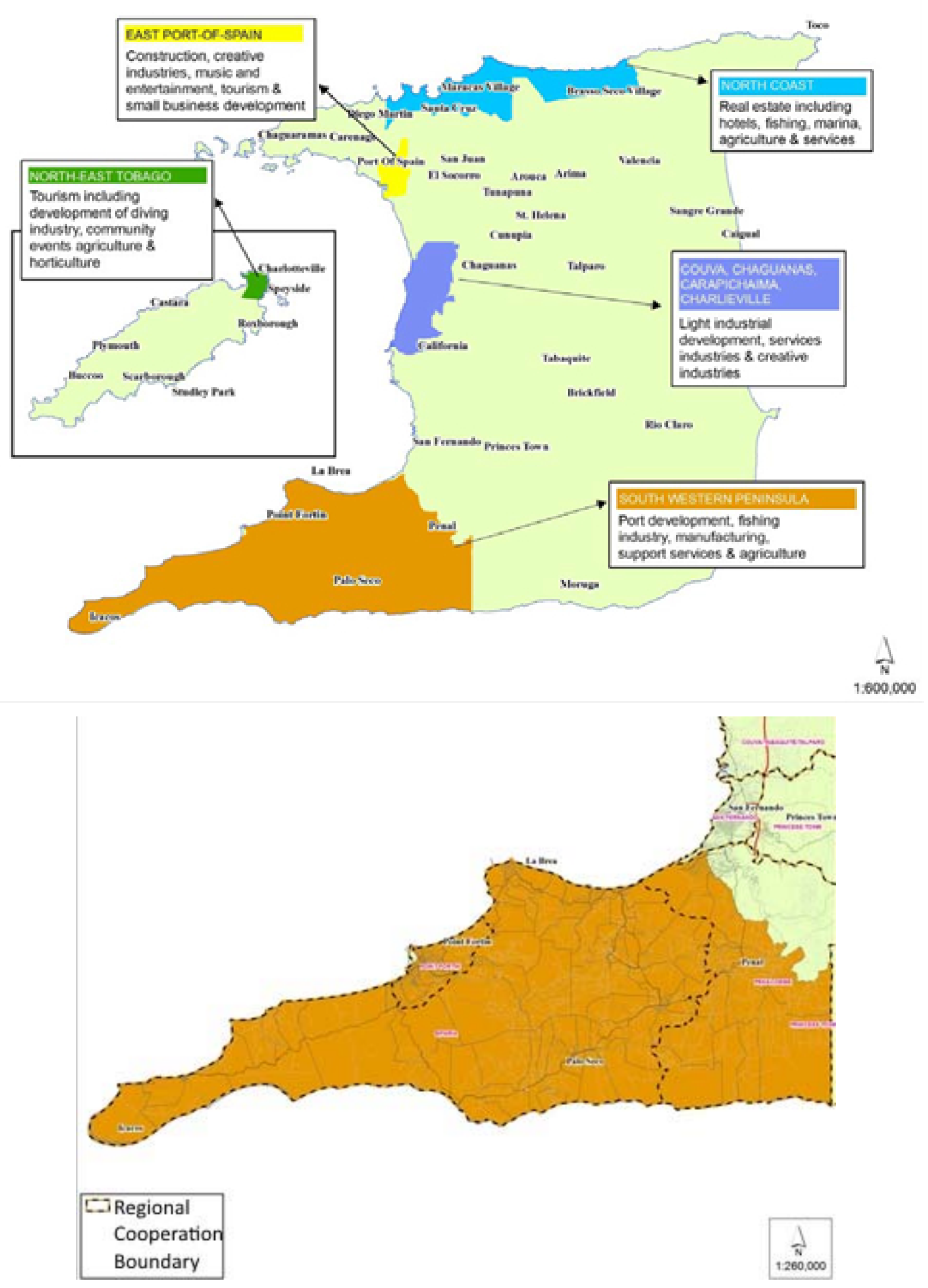

Figure 3. Growth poles of Trinidad and Tobago. 


\section{Project Matrix Applied}

In accordance with the interaction matrix shown in Table 1, Section I, the project team applied project indicators (see Table 2) to ensure that the deliverables of the project were being met within the budget and timeframe expected. It is note worthy that ensuring project success is in itself an indicator of a sound interaction or collaboration.

Table 2

Showing the Project Matrix Applied

\begin{tabular}{|c|c|c|}
\hline Indicator & Measurement indicators & Means of verification \\
\hline \multirow{4}{*}{$\begin{array}{l}\text { Integrate public-private actors and build } \\
\text { institutional capabilities for the } \\
\text { implementation of the LED methodology. }\end{array}$} & Coordination committees established & Agendas of committee meetings \\
\hline & Training/workshops & Attendance registers and certificates \\
\hline & At least two exchange trips & Reports \\
\hline & $\begin{array}{l}\text { LED entity created and secures diversified } \\
\text { streams of funding }\end{array}$ & Financial statements \\
\hline \multirow{2}{*}{$\begin{array}{l}\text { Development of new or expanded } \\
\text { business activities in key non-energy } \\
\text { sectors (agriculture, fishing, and tourism) } \\
\text { in the region. }\end{array}$} & $\begin{array}{l}\text { Total of } 150 \text { small and medium enterpris } \\
\text { (SME) esestablished }\end{array}$ & Proof of registration \\
\hline & $\begin{array}{l}\text { Identification of at least five innovative } \\
\text { (financed) products }\end{array}$ & Financing agreements \\
\hline \multirow[b]{2}{*}{$\begin{array}{l}\text { Support human capital development and } \\
\text { employability of marginalized and at risk } \\
\text { groups in the region. }\end{array}$} & $15 \%$ decrease in school drop-out rate & Register of students completing school \\
\hline & $\begin{array}{l}\text { 75\% of at risk youth participating in } \\
\text { sporting programmes showing } \\
\text { improvement in behaviour and academic } \\
\text { performance }\end{array}$ & Evaluation reports \\
\hline \multirow{3}{*}{$\begin{array}{l}\text { Creating and transferring knowledge, } \\
\text { results, and best practices on LED in } \\
\text { extractive industries regions to key } \\
\text { stakeholders groups. }\end{array}$} & Creation of LED guide & Guidelines submitted \\
\hline & Case study written & Publications \\
\hline & \begin{tabular}{|l} 
Adoption of extractive industries \\
transparency initiative (EITI) standards
\end{tabular} & Policy adjustments \\
\hline
\end{tabular}

\section{Interaction Matrix Applied}

The interaction matrix was applied according to Table 3 below.

Table 3

The Interaction Matrix Applied

\begin{tabular}{|l|l|l|}
\hline Indicator & Measurement indicators & Means of verification \\
\hline $\begin{array}{l}\text { Similar vision-to see greater impact of } \\
\text { investment by Atlantic liquefied natural } \\
\text { gas (ALNG) into sustainable development } \\
\text { initiatives in the south western region of } \\
\text { Trinidad. }\end{array}$ & Consistent message by each partner & Mission and vision statements \\
\hline Commitment to fund the project & Negotiations on budget requirements & Financial agreement signed \\
\hline $\begin{array}{l}\text { Agreement to share the new knowledge } \\
\text { generated. }\end{array}$ & $\begin{array}{l}\text { Included in initial concept and project } \\
\text { design }\end{array}$ & Contractual terms and conditions signed \\
\hline $\begin{array}{l}\text { To participate actively in project } \\
\text { meetings-ensure that there is no need to } \\
\text { adjust roles, responsibilities, etc.. }\end{array}$ & $\begin{array}{l}\text { Steering committee established to meet } \\
\text { once a month }\end{array}$ & Report \\
\hline $\begin{array}{l}\text { Explore possible future/long term } \\
\text { collaborations. }\end{array}$ & Ongoing discussions & New proposal concepts being designed \\
\hline $\begin{array}{l}\text { Outreach and national } \\
\text { development-investing in people. }\end{array}$ & $\begin{array}{l}\text { SMEs developed and funded, greater } \\
\text { retention of school aged children, linkages } \\
\text { in the business sector }\end{array}$ & $\begin{array}{l}\text { Registration of businesses, funding } \\
\text { agreements, improved school pass rates }\end{array}$ \\
\hline
\end{tabular}




\section{Section III: Conclusions and Recommendations}

\section{Conclusions}

The "interaction" must not be seen as an end in itself, but rather the beginning of a mutually beneficial relationship whose output serves to benefit a much wider area. It must also be seen as investments in identifying opportunities for future interactions.

Indicators are critical and so is the selection of appropriate measurements to be applied. Indicators are not to be viewed as static but as dynamic, and therefore, must be carefully monitored as they may need to change. This requires a degree of flexibility and agility within partners to cater for changes in the environment within which the joint effort is taking place and the incorporation of these changing indicators. Indicators also vary according to the type and nature of university-industry collaboration (see Figure 4). Over time, if the interaction persists and multiple interactions are realized, one will observe that the family of indicators or the emphasis on individual indicators may vary.

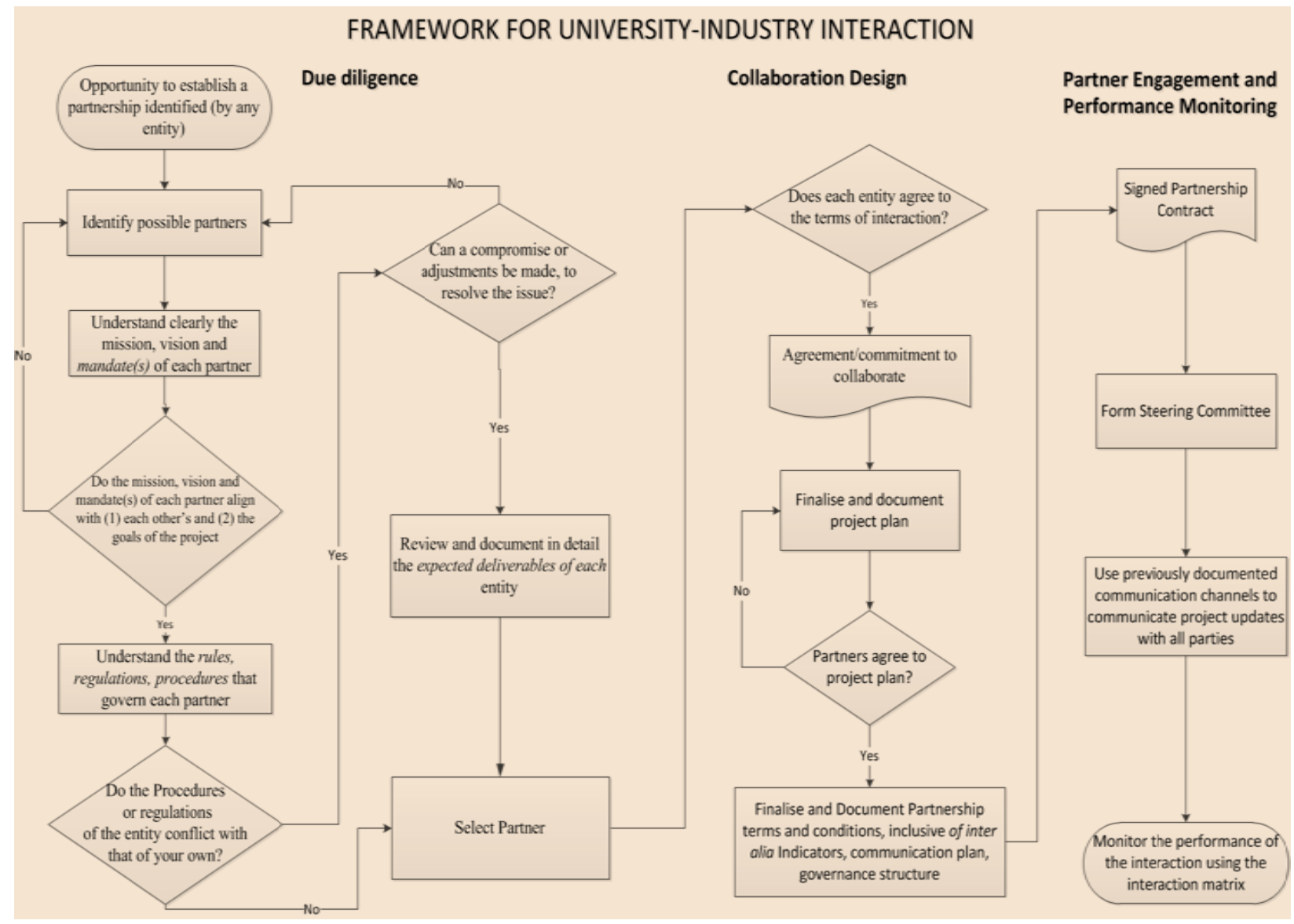

Figure 4. Framework for university-industry interaction.

Constant communication is necessary to facilitate these amendments in a smooth and timely manner. The intensity of the collaboration canvary as required, but governed at the very least by a formal agreement. Frequent interaction and discussion increase the chances of tacit knowledge transference, and therefore, increase the opportunity for learning from each other. 
Agreement on indicators "prior to initiation" of the intervention or project may require consultation with main partners, peripheral partners, and beneficiaries. Each entity/partner will measure the success of the initiative/intervention against differing sets of indicators or measures depending on their mission, vision, and business proposition. Agreement and documentation at this stage is very important.

Finally, the interaction will persist as long as all partners maintain a committed position throughout the interaction. If, however, during the life of the interaction, a partner defaults on its commitment position, then the system becomes compromised.

\section{Recommendations for Creating a Successful Interaction}

Four critical steps are identified for a successful interaction from pre engagement to execution.

Step 1. Prior to formally engaging partners, it is advisable to conduct due diligence by:

1. Understanding clearly the mandate(s) of each partner;

2. Understanding the rules, regulations, and procedures that govern each entity;

3. Having the expectations of each entity properly articulated and documented interalia impact of activity or output, visibility, level of documentation;

4. Having a good understanding of the issue to be resolved or addressed and what are the impacting issues and peripheral relationships.

This set of pre-activity helps to determine whether there are grounds for a viable and sustainable interaction.

Step 2: Design the collaboration.

1. Agree on the scope of the project/the intervention, etc. "Garbage in, garbage out;"

2. Indicate the timelines, activities, resources, and measurements of performance;

3. Design a system to measure the health of the interaction—what is the overarching set of interaction indicators;

4. Establish an open form of communication.

Step3: Engage partners.

1. It is advisable that the contract governing the arrangement is one in which each partner has had ample input. This ensures that all parties' interests are catered for and each protected.

2. Constitute a project steering committee that meets at an agreed upon timeframe to discuss the performance of the contract (adherence, necessity for any changes to be discussed). This ensures that communication lines are kept open and expectations are on track.

3. Document and share proceedings of meetings, decisions, and changes.

Step 4: Monitor the performance of the interaction, by applying the interaction matrix.

The conditions under which the attainment of the outcome(s) of the interaction are specified must be carefully nurtured and monitored for signs of change. Any changes in various factors will influence the terms and conditions of the interaction and will call on each partner's ability to modify its approach.

Figure 5 summarises, in its entirety, the concept of a well-articulated university-industry collaboration. It depicts the main partners as the UWI, the IDB, and ALNG. The primary interaction or collaboration will be greatly facilitated, realising greater impact and return on investment if it can enjoy the enabling environment of the government. The beneficiary must retain its position as the focus of the intervention or collaboration. Once, all these parts work together and are monitored for performance, both collectively as a partnership and as individual entities, the desired outcome will be achieved. 


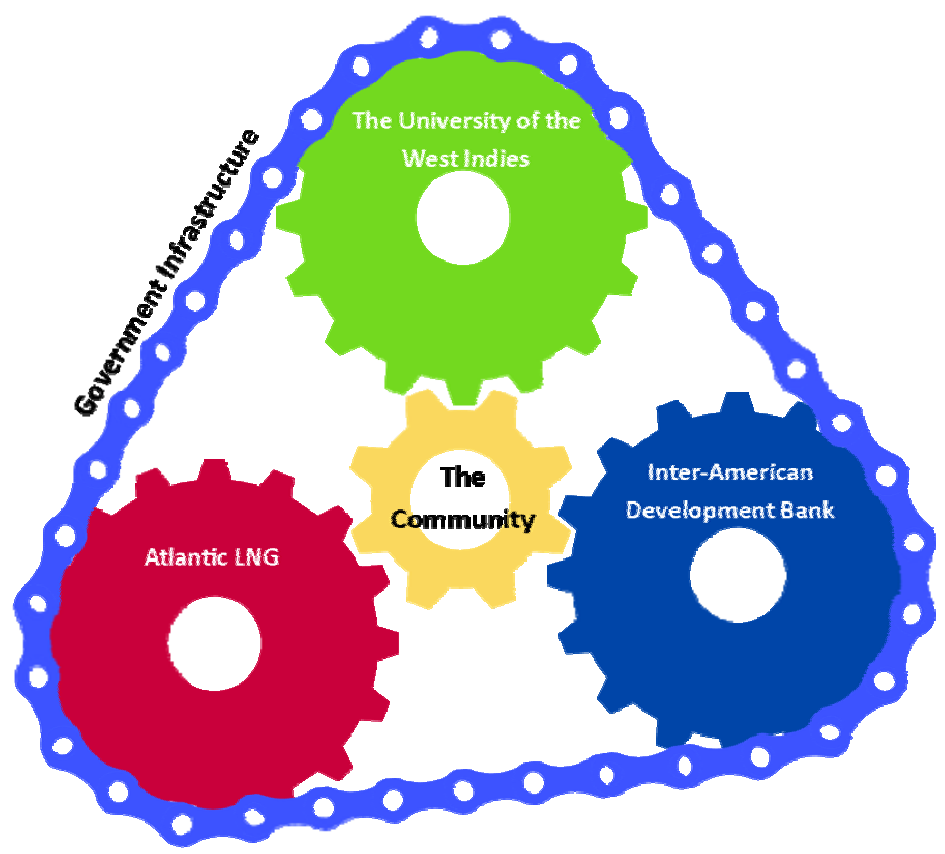

Figure 5. Illustration of the relationship among university-industry collaborators.

\section{References}

Clark, B. R. (1998). Creating entrepreneurial universities: Organizational pathways of transformation. Issues in higher education. The Education Resources Information Center \# ED421938.

Cyert, R. M., \& Goodman, P. S. (1997). Creating effective university-industry alliances: An organizational learning perspective. Organizational Dynamics, 25(4), 45-57.

Drucker, P. F. (1969). The age of discontinuity (Chapter 12). Elsevier Ltd..

Eliezer, G. E., \& Rubenstein, A. H. (1989). University-industry relations, a review of the major issues, in corporate research and development (pp. 43-62). The Industry-Government Relationship, Kluwer Academic Publications.

Hart, K., Laville, J., \& Cattani, A. D. (2010). The human economy. Authors’ comments.

Hart, K., Laville, J., \& Cattani, A. D. (Eds.). (2010). Building the human economy together. In The human economy (Chapter I). Polity Press.

James, R. H., \& Heim, A. A., (1997). Promoting economic development through university and industry partnerships. New Directions for Higher Education, Josey-Bass Publications Spring 1197, \# 97.

Korff, P. C., N., Baaken, T., \& Macpherson, G. (2013). University-industry linkage evolution: An empirical investigation of relationship success factors. $R$ \& D Management, 43, 365-380.

Marzo-Navarro, M., Pedraja-Iglesias, M., \& Rivera-Torre, P. (2009). The marketing approach in relationships between universities and firms. Journal of Relationship Marketing, 9, 127-147.

Plewa, C, Korff, N., Baaken, T., \& Macpherson, G. (2013). University-industry linkage evolution: An empirical investigation of relationship success factors. $R \& D$ Management, 43, 365-380.

Porter, M. E. (1990). The competitive advantage of nations. Harvard Business Review, March-April.

Porter, M. E. (1998). Clusters and the new economics of competition. Harvard Business Review, November-December, 77-90.

Seidman, D. (2014). From the knowledge economy to the human economy. Harvard Business Review. Retrieved November 12, 2014, from https://hbr.org/2014/11/from-the-knowledge-economy-to-the-human-economy

Seppo, M., \& Lilles, A. (2012). University of Tartu, discussions on Estonian economic policy. Theory and Practice of Economic Policy, 20(1).

United Nations Educational, Scientific, and Cultural Organization [UNESCO]. (2000). The Management of university-industry relations. Provides five institutional case studies from Africa, Europe, Latin America and the Pacific region that exemplify non-traditional activities partnership and business engageme. 